\title{
SERVICIOS PREVENTIVOS DE ASESORÍA Y ADVERTENCIA DE LAS AUDITORÍAS INTERNAS
}

\section{ADVISORY SERVICES AND PREVENTIVE WARNING FOR INTERNAL AUDITS}

\section{Flora Calderón Ramos ${ }^{1}$}

Recibido: 30/04/2020

Aprobado: 15/11/2021

\section{RESUMEN}

Esta investigación tiene como propósito mostrar cómo se abordan los servicios preventivos de asesoría y advertencia por parte de las Unidades de Auditoría Interna (UAI), la cual se efectúa bajo un enfoque metodológico cuantitativo y de tipo descriptivo, y se basa en los resultados seleccionados de un cuestionario de 50 preguntas, dividido en las siguientes categorías de análisis que apoyan la investigación: metodologías de las UAI utilizadas para brindar servicios preventivos de asesoría $y$ advertencia; utilidades de este tipo de servicios; $y$ dificultades que se presentan para poder realizarlos; aplicado a jefaturas y personal técnico colaborador de 22 UAI del sector público costarricense. Los resultados obtenidos muestran que, en su mayoría, se utiliza un instrumento de gestión para llevar a cabo dichos servicios; además, se atienden de forma permanente las solicitudes de asesorías o advertencias que surgen y se emiten conforme al ordenamiento jurídico y técnico costarricense.

PALABRAS CLAVE: ADMINISTRACIÓN PÚBLICA, CRITERIOS, CONSEJOS, FISCALIZACIÓN, HACIENDA PÚBLICA, INCUMPLIMIENTOS, INSTRUMENTO DE GESTIÓN, MECANISMOS DE CONTROL, OMISIÓN, ÓRGANO RECTOR, VALOR AGREGADO, VINCULANTE.

CLASIFICACIÓN JEL:M420

\section{ABSTRACT}

The purpose of this research is to show how advisory and preventive services are approached by the Internal Audit Units (IAU), which is carried out under a quantitative and descriptive methodological approach, and is based on the results selected from a questionnaire of 50 questions, divided into the following categories of analysis that support the research: UAI methodologies used to provide warning services and preventive advice; utilities of this type of services; and difficulties that arise to be able to carry them out; applied to heads and collaborating technicians of 22 UAI of the Costa Rican public sector. The results obtained

1 Investigador independiente; Código Postal 11401; San José, Costa Rica; fcalderonr2@gmail.com 
show that, for the most part, a management instrument is used to carry out these services. In addition, requests for advice or warnings that arise and are issued in accordance with the Costa Rican legal and technical system are permanently attended to.

KEYWORDS: PUBLIC ADMINISTRATION, CRITERIA, SUPERVISION, PUBLIC FINANCE, BREACHES, MANAGEMENT INSTRUMENT, CONTROL MECHANISMS, OMISSION, GOVERNING BODY, ADDED VALUE, BINDING.

JEL CLASSIFICATION: M420

\section{INTRODUCCIÓN}

Esta investigación comprende el análisis de los servicios preventivos de asesoría y advertencia que brindan las unidades de auditoría interna; para lo cual, se obtuvo una muestra de 22 unidades de auditoría interna del ámbito público nacional de Costa Rica, en el periodo comprendido de enero de 2017 a noviembre de 2018. Dichas UAI se ubican en diversas instituciones de la Administración Pública; cabe agregar que esta última se divide en administración pública central, la cual comprende los tres poderes de la república y el Tribunal Supremo de Elecciones; administración pública descentralizada, tanto institucional como territorial; $y$, las demás entidades de derecho público.

A nivel nacional, el tema de servicios preventivos de asesoría y advertencia se plantea en la Ley General de Control Interno, Ley 8292 (Asamblea Legislativa de la República de Costa Rica, 2002), la cual dispone en el artículo 22 inciso d), que el auditor interno debe asesorar, en materia de su competencia, al jerarca del cual depende; además, advertir a los órganos pasivos que fiscaliza sobre las posibles consecuencias de determinadas conductas o decisiones, cuando sean de su conocimiento.

A nivel internacional, el Instituto Internacional de Auditores Internos (2017) señala que estos "son por naturaleza consejos, y son desempeñados, por lo general, a pedido de un cliente" (p. 2).

Por lo tanto, es importante mencionar como limitación al alcance de la investigación, que no se encontró literatura asociada con la prestación de este tipo de servicios, y tal como se observa en los párrafos anteriores, la normativa es muy general, por lo tanto, deja vacíos en el buen tratamiento de estos, dado que se refiere al deber de realizarlos, no así, la forma en la cual se deben ejecutar.

Es en este punto particular, que la presente investigación es importante, por cuanto es el primer artículo que analiza la implementación de los servicios preventivos en el sector público costarricense; en la cual, mediante el diagnóstico de las metodologías utilizadas para la ejecución de servicios preventivos de asesoría y advertencia por parte de las UAI bajo estudio, las personas encargadas de las auditorías conozcan los resultados, y esto les permita promover mejoras en la realización de este tipo de servicios dentro de sus organizaciones.

De acuerdo con lo anterior, se establece como objetivo general de la investigación "Analizar la forma en que las auditorías internas del sector gubernamental costarricense ejecutan metodologías, para prestar servicios preventivos de asesorías y advertencias; además, establecer las utilidades y dificultades que se generan de estos"; y como objetivos específicos los siguientes:

1. Diagnosticar la metodología empleada por las unidades de auditoría interna del sector público costarricense para realizar servicios preventivos de asesoría y advertencia.

2. Identificar las utilidades que se derivan de los servicios preventivos de asesorías y advertencias para las instituciones públicas cuando las UAI del sector gubernamental desarrollan estos servicios.

3. Conocer las dificultades que experimentan las UAI gubernamentales cuando realizan servicios preventivos de asesorías y advertencias. 
Los elementos que orientan la investigación se enmarcan desde los ejes temáticos vinculados a la auditoría interna en el sector público costarricense, hasta los servicios preventivos de asesoría $y$ advertencia; con la finalidad de contar con referentes teóricos para posteriormente interpretar los resultados de la investigación.

\section{Unidades de Auditoría Interna}

La Ley General de Control Interno regula el marco normativo base de las auditorías internas del sector público; y conceptualiza a la auditoría interna como "la actividad independiente, objetiva $y$ asesora, que proporciona seguridad al ente u órgano, puesto que se crea para validar y mejorar sus operaciones" (Asamblea Legislativa de la República de Costa Rica, 2002, art.21).

Esta definición resalta el requerimiento de que la función de auditoría interna se desarrolle de forma independiente y objetiva dentro de la organización a la que pertenece; también es asesora, lo que le permite coadyuvar en la validación y mejoramiento de las operaciones de la entidad, tal como lo describe el artículo 22 inciso d) de la Ley 8292 citado anteriormente.

A esto se añade el objetivo de la auditoría interna, el cual es "prevenir, asistir y asesorar a la Administración, sobre el marco de obligaciones y responsabilidades que deben cumplir en su desempeño; proporcionando los análisis, las valoraciones, las recomendaciones, los consejos y la información concerniente a las actividades auditadas" (Contraloría General de la República, 2018, p. 5).

Lo anterior se resume en que la auditoría interna ha sido concebida para prevenir, asistir y asesorar a la administración, tomando como referencia el logro de los objetivos institucionales, a través de análisis, valoraciones y las recomendaciones que emita; de esta forma, agrega valor y proporciona a la ciudadanía una garantía razonable de que la actuación de la administración se realiza conforme a las sanas prácticas y al marco legal y técnico.

\section{Servicios preventivos de asesoría}

La asesoría que brindan los auditores internos es parte de los servicios preventivos que se les atribuye por medio de las competencias, según el artículo 22, inciso d) de la Ley 8292 (Asamblea Legislativa de la República de Costa Rica, 2002), el cual indica "Asesorar, en materia de su competencia, al jerarca del cual depende"; por lo tanto, puede brindar asesoría en temas de su competencia al jerarca.

También, la Contraloría General de la República, grupo de Auditores Internos del Sector Público (2012), sobre el servicio de asesoría de las auditorías internas del sector público, señala lo siguiente:

El servicio preventivo de asesoría consiste en proveer a la Administración Activa (fundamentalmente al jerarca, aunque no de manera exclusiva, según determine el Auditor) criterios, opiniones, sugerencias, consejos u observaciones en asuntos estrictamente de la competencia de la Auditoría Interna, con la intención de que se conviertan en insumos para la administración activa, que le permitan tomar decisiones más informadas y con apego al ordenamiento jurídico y técnico, sin que se menoscaben o comprometan la independencia y la objetividad de la Auditoría Interna en el desarrollo posterior de sus demás competencias (p.1).

Es decir, a través del servicio preventivo de asesoría, la auditoría interna provee al jerarca y a quién estime conveniente entre otros, criterios, opiniones, sugerencias, consejos u observaciones; en temas que son de su competencia; los cuales sirven de insumo a la administración para tomar decisiones de forma más apropiada, puesto que para emitirlos, se debe considerar el ordenamiento 
jurídico y técnico; además, conlleva elementos de independencia y objetividad, que los hace más sólidos y creíbles; a su vez, puede desarrollar posteriormente estudios relacionados con los asuntos asesorados.

\section{Servicios preventivos de advertencia}

Según el artículo 22, inciso d) de la Ley 8292 (Asamblea Legislativa de la República de Costa Rica, 2002), "advertir a los órganos pasivos que fiscaliza sobre las posibles consecuencias de determinadas conductas o decisiones, cuando sean de su conocimiento"; por lo tanto, en caso de que la auditoría interna tenga conocimiento de una conducta o decisión realizada por el órgano pasivo, el cual pueda generar un impacto negativo en la institución, debe prestarle estos tipos de servicios.

Al respecto, no es solamente que el auditor interno haga del conocimiento de la administración las malas conductas o acciones identificadas, sino también, las posibles consecuencias de estas con la debida justificación. Así pues, se puede denominar a las advertencias como:

... un servicio preventivo que consiste en alertar a los órganos pasivos de la fiscalización, incluido el jerarca, sobre las posibles consecuencias de asuntos que llegan al conocimiento de la Auditoría Interna, y sobre conductas o actuaciones que podrían estar contraviniendo el ordenamiento jurídico y técnico o exponiendo a riesgo a la institución (Contraloría General de la República, grupo de Auditores Internos del Sector Público, 2012, p. 8).

Así las cosas, la razón de ser de la advertencia es alertar a los órganos pasivos sobre posibles infracciones cometidas tras incumplir alguna norma del ordenamiento jurídico, lo cual puede causar una afectación negativa a la gestión de la institución, al exponerla ante un riesgo.

Respecto al marco conceptual, se indica que la investigación se realiza en una muestra representativa de las diferentes instituciones que conforman el aparato estatal costarricense; esto con el fin de tener una visión más amplia de la situación actual sobre los servicios preventivos de asesorías y advertencias brindadas por las UAI, en sus respectivas instituciones y no de un solo sector en específico.

\section{METODOLOGÍA}

A continuación se indica el diseño metodológico que orienta el desarrollo de la investigación.

\section{Enfoque de investigación}

Se considera que esta investigación es de enfoque cuantitativo; según las afirmaciones de Hernández Sampieri et al. (2014): "Utiliza la recolección de datos para probar hipótesis con base en la medición numérica y el análisis estadístico, con el fin establecer pautas de comportamiento y probar teorías" (p. 4).

De acuerdo con lo anterior, en el presente estudio se determina, por medio de la recolección y tabulación de datos estadísticos, la percepción de los responsables de las UAI seleccionadas respecto a la situación actual de cómo se llevan a cabo los servicios preventivos de asesorías y advertencias. 


\section{Tipo de investigación}

El alcance de la investigación es de tipo descriptivo; Hernández Sampieri et al. (2014) sobre este menciona que "Busca especificar propiedades y características importantes de cualquier fenómeno que se analice. Describe tendencias de un grupo o población” (p. 92).

$\mathrm{Al}$ respecto, las propiedades y características del fenómeno que citan los autores se pueden ver reflejadas en el presente estudio, pues se busca analizar la forma en que las UAI del sector público realizan los servicios preventivos de asesorías y advertencias.

\section{Población y muestra}

La población de interés participante en esta investigación comprende 219 unidades de auditoría interna, que corresponden a la totalidad de las UAI del sector público costarricense, conformadas por auditorías internas unipersonales y aquellas que disponen de hasta 60 funcionarios.

Para la selección de la muestra, se utilizaron dos criterios; el primero se refiere a un muestreo probabilístico el cual se aplicó a 7 estratos en los que se dividió la población; $y$ un segundo criterio para el estrato 8 de la población. Respecto al primer criterio, según Hernández Sampieri et al. (1991) se aplica cuando "la población se divide en segmentos y se selecciona una muestra para cada segmento" (p. 181); es decir, de la población anteriormente señalada, se determinó una muestra de 17 UAI, la cual se aplicó a los estratos señalados, para lo cual se definió por estrato la cantidad de UAI a seleccionar.

En cuanto al segundo criterio, se consideró oportuno ampliar los datos por las características de la investigación, de modo que se sumaron cinco más a criterio del investigador; así las cosas, la suma de la muestra fue de 22 UAI; para la selección, se utilizó el muestreo al azar del software de auditoría IDEA.

\section{Fuentes de información}

Respecto a las fuentes primarias, estas hacen referencia a aquellas que proporcionan datos de primera mano; por lo cual, se considera que para esta investigación están conformadas por un solo cuestionario, el cual se aplicó al personal competente de las UAI seleccionadas.

Por su parte, las fuentes de información secundarias, corresponden a la investigación bibliográfica en la que se basa la presente investigación. Dichas fuentes comprenden entre otras: libros alusivos a la temática, revistas y artículos científicos, tesis de grado y posgrado, archivos institucionales. Además, se realizó una búsqueda electrónica por medio de plataformas como EBSCO, E libro y las direcciones electrónicas de las diferentes instituciones.

\section{Instrumentalización}

Se aplicó un cuestionario tipo Likert para obtener la información a analizar, que de acuerdo con Hernández Sampieri et al. (2014) es el: "Conjunto de ítems que se presentan en forma de afirmaciones para medir la reacción del sujeto en tres, cinco o siete categorías" (p. 238).

En relación con lo anterior, para facilitar la recolección, tabulación y validación de la información a recibir de la percepción de los sujetos participantes, se utilizó para este tipo de cuestionario un escalamiento de siempre, algunas veces y nunca, el cual contó con un total de 50 preguntas. 


\section{Validación de instrumentos}

El instrumento de consulta se elaboró a partir de la operacionalización de los objetivos y fue validado por tres expertos auditores, quienes revisaron el cuestionario y emitieron criterios para ajustarlo. Además, se aplicó una prueba piloto del instrumento, en la cual se solicitó la colaboración a profesionales que trabajan en UAI, las cuales no eran parte del estudio; con el propósito de probar el instrumento, en cuanto a redacción, vocabulario, comprensión. De la misma manera, se recogieron las observaciones y recomendaciones, y se afinó el instrumento, de modo que fuera más objetivo y técnico.

\section{Proceso de análisis}

El instrumento de consulta se aplicó tanto a los encargados de las UAI seleccionadas, como al personal técnico colaborador de estas. A partir de los resultados obtenidos, se realizó un análisis descriptivo de cada una de las categorías de análisis definidas en el estudio.

\section{RESULTADOS}

Las categorías de análisis que sustentan la investigación son las siguientes:

1. Metodologías de las UAI utilizadas para brindar servicios preventivos de asesoría y advertencia.

2. Utilidades de este tipo de servicios.

3. Dificultades que se presentan para poder realizarlos.

\section{Presentación y análisis de los resultados}

De previo a detallar los resultados obtenidos, se indica que las personas quienes colaboraron completando el instrumento de consulta, corresponden a profesionales inmersos en todos los procesos de las UAI; por lo tanto, se obtuvo la percepción de los puestos de mando y del personal técnico colaborador de las UAI muestreadas.

\section{Metodologías de las UAI utilizadas para brindar servicios preventivos de asesoría y advertencia}

Para la primera categoría de análisis de este estudio, se efectuaron 27 preguntas, de las cuales, para efectos de análisis, se despliegan los porcentajes de los ítems 1, 4, 10, 17, 21, 26 y 27, pues se consideran que son las puntuaciones más destacadas o relevantes para las percepciones favorables y desfavorables; con la finalidad de contrastar las opiniones de la población objeto de estudio, de acuerdo con el sustento teórico y conceptual de la investigación. Además, los Anexos 1 y 2 muestran los cuestionarios completos aplicados.

Con respecto al uso por parte del personal encargado de las auditorías internas de un instrumento de gestión (físico o digital), para realizar los servicios preventivos de asesoría y advertencia, destacan con un $68 \%$ a favor de la siguiente afirmación de Arellano Elizalde et al. (2013) "de la metodología en un trabajo de investigación es importante ya que gracias a ella se puede fundamentar la evidencia que se ha obtenido en una auditoría interna” (p. 91); por su parte, un $82 \%$ del personal técnico colaborador lo confirma; es decir, en su mayoría, las UAI 
están brindando este tipo de servicios a través de mecanismos previamente establecidos para la consecución de los objetivos que se persiguen con estos.

No obstante, según la percepción de las personas encuestadas, existen UAI que no cuentan con una herramienta para facilitar la consecución de dichos servicios. Por lo tanto, algunas podrían estar dejando de fundamentar evidencia respecto a los servicios preventivos prestados en razón de no utilizar un instrumento guía del quehacer de estos. Como puede observarse, el uso de herramientas de gestión es fundamental por cuanto sirve de apoyo en la prestación de estos servicios; además, coadyuva en el cumplimiento de objetivos propuestos.

En cuanto a la percepción del personal a cargo de las UAI, sobre la planeación de metas de mediano plazo para la prestación de estos servicios, un $68 \%$ considera que nunca sucede.

Con referencia a lo anterior, existe una tendencia desfavorable sobre la planificación de estos servicios a mediano plazo; en este sentido, las Normas para el ejercicio de la Auditoría Interna en el Sector Público establecen en el acápite 2.7 "En el caso de los servicios preventivos, la planificación puntual se debe realizar en lo que resulte procedente" (Contraloría General de la República, 2009, p. 8); como se puede entender, no siempre se logran planificar este tipo de servicios dada la oportunidad que requieren; no obstante, cuando sea posible, si se deben programar estos estudios.

Ahora bien, la consideración favorable de los auditores internos es consecuente con lo que menciona Murgueytio Montenegro (2017) respecto a la auditoría interna:

(...) se le atribuye el nivel de asesora, además de tener la ventaja de relacionarse constantemente con las operaciones, lo que le permite conocerla a fondo, cuestionar su actividad bajo el principio de mejora continua, relegando el criterio de que todos los procesos están consumados y no hay posibilidades de mejorarlos (p. 33).

Como resultado de lo anterior, se comprueba que la auditoría interna puede programar servicios preventivos de asesoría y advertencia, puesto que maneja suficiente conocimiento de la organización; esto le permite definir asuntos pertinentes y el momento propicio en el que puede brindarlos.

Respecto a la consideración por parte de las UAI de las solicitudes de asesoría realizadas por el jerarca; según los datos aportados por el personal a cargo de las Auditorías Internas, el 86\% siempre toma en cuenta las solicitudes de asesoría que realiza el jerarca de su institución y un 14\% solo algunas veces, de lo cual se desprende que para el servicio preventivo de asesoría, las UAI están cumpliendo permanentemente el cometido de brindar este servicio al jerarca; en este sentido, la Contraloría General (2009) señala:

Es un servicio dirigido al jerarca y consiste en el suministro de criterios, observaciones y demás elementos de juicio para la toma de decisiones con respecto a los temas que son competencia de la auditoría interna. También puede ser brindado a otras instancias institucionales, si la auditoría interna lo considera pertinente (p. 12).

En concordancia con dicha definición, se evidencia que efectivamente el servicio de asesoría es brindado al jerarca cuando este lo solicita y coadyuva en la toma de decisiones al propiciar el buen gobierno de la organización. Además, el artículo 22, inciso d) de la Ley 8292 (Asamblea Legislativa de la República de Costa Rica, 2002), indica "Asesorar, en materia de su competencia, al jerarca del cual depende"; es decir, las UAI pueden brindar asesorías en temas de su competencia al jerarca.

En tal sentido, a través del servicio preventivo de asesoría, la auditoría interna provee al jerarca o a quién estime conveniente, criterios, opiniones, sugerencias, consejos u observaciones; los cuales sirven de insumo al jerarca $y$, por ende, a la administración para tomar decisiones de forma más apropiada, puesto que para emitirlos, se debe considerar el ordenamiento jurídico y técnico; 
además, conlleva elementos de independencia y objetividad, que los hace más sólidos y creíbles; a su vez, puede desarrollar posteriormente estudios relacionados con los asuntos asesorados.

Sobre la percepción del personal encargado de la auditoría interna de la importancia de brindar los servicios de asesoría, el 100\% considera que siempre es necesario brindarlos a la Administración Activa; asimismo, el 89\% del personal técnico colaborador opina de la misma forma.

En relación con este ítem, la Contraloría General de la República, grupo de Auditores Internos del Sector Público (2012), señala "la asesoría es un mecanismo para que la Auditoría Interna agregue valor a la gestión institucional, $y$ contribuya al logro de los objetivos y a la rendición de cuentas" (p. 2); por lo cual, se denota que efectivamente hay un interés por parte del personal a cargo de las UAI, de brindar estos servicios; generando valor por cuanto se contribuye con el logro de los objetivos instituciones y la rendición de cuentas.

Asimismo, la Defensoría de los Habitantes de la República (2016), en su Manual de procedimientos de la auditoría interna, define a dicha unidad como "un mecanismo más de control que desempeña una función asesora y de servicio que agrega valor a la gestión institucional y apoya a la administración" (p. 12).

En consecuencia, la auditoría interna representa una línea de defensa contra los riesgos que se pueden materializar sin un adecuado control; buscando agregar valor a la gestión institucional a través de los servicios que realiza. Por lo tanto, se evidencia que las UAI le toman importancia a este tipo de servicios, y están al tanto de los requerimientos de la administración activa. Así mismo, quienes respondieron a veces o nunca, están desvalorizando el beneficio que genera el brindar estos servicios a la administración.

Seguidamente, se presenta la opinión de las personas encuestadas respecto a si consideran que la administración comprende que la importancia de las advertencias radica en prevenir una afectación negativa a la gestión institucional; para un $68 \%$ del personal encargado de las auditorías internas, siempre es así y el 32\% restante considera que algunas veces; respecto al personal técnico colaborador, un $57 \%$ opina que siempre, un $39 \%$ considera que algunas veces y un $4 \%$ considera que nunca.

En lo tocante a este aspecto, la Contraloría General de la República, grupo de Auditores Internos del Sector Público (2012), agrega que los servicios preventivos de advertencias alertan "sobre conductas o actuaciones que podrían estar contraviniendo el ordenamiento jurídico y técnico o exponiendo a riesgo a la institución" (p. 8); es decir, estos servicios coadyuvan en el resguardo de la gestión institucional al alertar sobre posibles faltas al ordenamiento jurídico y técnico, por lo que se les debe tomar la debida importancia.

En razón de ello, la UAI aparte de actuar con el debido conocimiento jurídico y técnico, también debe estar atenta respecto a posibles riesgos que incidan de forma negativa en la organización y proyectar su trabajo de forma adecuada hacia afuera, porque la administración debe estar consciente de que estos servicios coadyuvan en su gestión.

De hecho, la advertencia según la Contraloría General de la República (2009), "Es un servicio dirigido a los órganos sujetos a la competencia institucional de la auditoría interna, y consiste en señalar los posibles riesgos y consecuencias de determinadas conductas o decisiones" (p. 12); por lo tanto, es un instrumento de la UAI para avisar cuando sea conocimiento de la auditoría interna, algún posible efecto negativo por actuación del órgano pasivo.

Debido a esto y ante la respuesta del personal encargado de las UAI, es necesario promover la importancia de brindar estos servicios, de modo que cambie el panorama y la administración considere importante realizarlos.

Adicionalmente, se observó que un $68 \%$ de las personas encargadas de la auditoría interna considera que siempre confronta y analiza las acciones tomadas por la administración con respecto a los asuntos objeto de advertencia, mientras que un 32\% indicó que algunas veces lo realiza. Por 
su parte, el personal técnico colaborador considera en un $62 \%$ que siempre es así, un 34\% algunas veces $y$ un $4 \%$ nunca.

En relación con este ítem, la Defensoría de los Habitantes de la República (2016), indica "De manera posterior, se verifican las acciones tomadas por la administración con respecto a los asuntos objeto de advertencia" (p. 15). En este sentido, la UAI debe vigilar las acciones que a efecto de las advertencias emitidas, el sujeto auditado realice; por cuanto, aunque el criterio de esta no es vinculante, la administración debe justificar las razones del por qué no se tomó en cuenta el criterio emitido producto de la advertencia en caso de que así resulte.

Además, la persona encargada de la UAI debe velar porque no haya un efecto negativo debido a que se haya pasado por alto la advertencia emitida. En este sentido, la Contraloría General de la República (2009) señala:

El auditor interno debe establecer, mantener y velar porque se aplique un proceso de seguimiento de las recomendaciones, observaciones y demás resultados derivados de los servicios de la auditoría interna, para asegurarse de que las acciones establecidas por las instancias competentes se hayan implementado eficazmente $y$ dentro de los plazos definidos por la administración (Norma 2.11).

Es decir, los auditores internos tienen la responsabilidad de brindar el debido seguimiento de los servicios preventivos, aún más de las advertencias. Asimismo, las Normas Internacionales para el ejercicio profesional de la auditoría interna, en la norma 1130.A3 señalan: "La actividad de auditoría interna puede proporcionar servicios de aseguramiento donde haya realizado previamente servicios de consultoría, siempre y cuando la naturaleza de los servicios de consultoría no cause impedimentos a la objetividad" (Instituto Internacional de Auditores Internos, 2017, p. 7); el realizar estudios posteriores de auditoría sobre un asunto previamente abordado por una advertencia; le permitiría a la persona encargada de la auditoría validar tanto las acciones tomadas por la administración como, si se materializó el efecto negativo que previó.

De ahí la importancia de que las UAI le den prioridad a confrontar y analizar las acciones de la administración sobre las advertencias, a efectos de resguardar a la organización de vulnerabilidades que se pueden dar.

Por lo tanto, un $68 \%$ y un $62 \%$ de las respuestas arriba indicadas, coincide con la necesidad de que la persona encargada de la UAI confronte $y$ analice los resultados obtenidos producto de las advertencias, $y$ vele porque no haya un efecto negativo, debido a que se haya pasado por alto la advertencia emitida. Es decir, las UAI deben darle siempre prioridad a confrontar y analizar las acciones de la administración sobre las advertencias; dada la importancia que ellas representan, a efectos de resguardar a la organización de vulnerabilidades que se pueden dar. En razón de ello, las restantes opiniones de las personas encuestadas deben procurar la realización del seguimiento posterior a las advertencias.

Por otra parte, se observa que un $77 \%$ de los auditores internos considera que siempre promueven la ejecución de los servicios preventivos de manera escrita. Al respecto, la Contraloría General de la República, grupo de Auditores Internos del Sector Público (2012) menciona “...de preferencia debe ser escrita" (p. 3); esto por cuanto, dependiendo de la complejidad del asunto, es necesario que quede documentado el consejo de la auditoría interna.

Además, respecto a llevar un registro de todos los servicios preventivos brindados, el $73 \%$ de las personas a cargo de la UAI señalan que siempre velan por ello; por otra parte, un $27 \%$ indica que algunas veces los llevan. Similarmente, el $84 \%$ del personal técnico colaborador opina que siempre velan porque así sea; un $9 \%$ indica que algunas veces y un $7 \%$ indica que nunca.

A propósito de este ítem, la Contraloría General de la República, grupo de Auditores Internos del Sector Público (2012) sugiere: "Llevar un registro de las asesorías prestadas por la 
Auditoría interna, tanto verbalmente como por escrito, que evidencie el uso de tiempo y recursos correspondientes" (p. 10). Puesto que todos los servicios de auditoría requieren de recursos, el llevar un control de estos le permitirá a la UAI tener un estimado de lo que conlleva la realización de los servicios preventivos; además, se dejará en evidencia que se están efectuando. Por lo tanto, se determina que esta práctica concuerda con la mayoría de las opiniones de las personas encuestadas; por su parte, el porcentaje restante debe procurar implementar y mejorar dicha práctica en las UAI.

\section{Utilidades de los servicios preventivos de asesorías y advertencias}

Para la segunda categoría de análisis de este estudio, se realizaron 9 preguntas, de las cuales, para efectos de análisis, se despliegan los porcentajes de los ítems 28, 31, 33, y 35, dado que obtuvieron las puntuaciones más destacadas o relevantes, altas y bajas, para las percepciones positivas y negativas; con la finalidad de contrastar las opiniones de la población objeto de estudio, de acuerdo con el sustento teórico y conceptual de la investigación. Además, los Anexos 1 y 2 muestran el cuestionario completo aplicado.

Con respecto a la elaboración de instrumentos e insumos para alertar posibles incumplimientos a la normativa, destacan, con un $27 \%$, las personas encargadas de las UIA que indican que siempre; un $32 \%$ señala que algunas veces y un 41\%, que representa la mayor proporción, considera que nunca. Por su parte, un 59\% del personal técnico colaborador opina que siempre lo realizan; un $34 \%$ señala que algunas veces; $y$ solo un $7 \%$ nunca.

Al respecto, Castilla Torres (2015) menciona "Se debe tener claro que la auditoría, además de los controles posteriores tradicionales, puede generar herramientas que minimicen la ocurrencia de los hechos anómalos detectados y en gran medida faciliten la labor de las entidades" (p.69). En este sentido, se presenta un grupo importante de las UAI consultadas, quienes implementan esta buena práctica, por lo cual, están generando instrumentos para alertar cuando la administración esté por tomar alguna decisión relacionada con un hecho anómalo detectado, de manera que se pueda prevenir y suministrar la debida justificación de forma oportuna.

Por otra parte, se determina que la mayoría de las UAI no elaboran instrumentos e insumos para alertar posibles incumplimientos de la normativa a la Administración Activa; por lo tanto, se percibe la necesidad de que se incorpore dicha práctica en todas.

Además, se le consultó a las personas encargadas de la UAI si ejecutan acciones para identificar, a través de los servicios preventivos, los posibles riesgos que afectarían de forma negativa a la gestión institucional; a lo cual se obtuvo como respuesta que un $68 \%$ de estos "siempre" lo hace; no obstante, un 23\% solo "algunas veces" y un 9\% "nunca". Similarmente, respecto a este enunciado se obtuvo como respuesta del personal técnico colaborador porcentajes parecidos: un $68 \%$ siempre, un $25 \%$ algunas veces y un $7 \%$ nunca.

$\mathrm{Al}$ respecto, se considera como una utilidad de los servicios preventivos la detección temprana de riesgos, de lo cual The Institute of Internal Auditors (2017) indica "la auditoría interna identifica los riesgos que pueden impedir que una organización alcance sus objetivos, alerta a los líderes sobre dichos riesgos y recomienda, de manera proactiva, mejoras para ayudar a reducir los riesgos" (p. 4).

Como se puede observar, en un alto porcentaje de las UAI se propicia la evaluación de riesgos, es decir las vulnerabilidades de la organización que pueden afectar el logro de los objetivos institucionales, a través de la asesoría y advertencia; esto les permite prevenir y brindar insumos a la administración para que conozca dichas vulnerabilidades y las atienda, de modo que se reduzca el impacto negativo en caso de ocurrir una situación o un evento que afecte la gestión institucional; no obstante, hay un porcentaje de personal encargado de la auditoría interna antepuestos a dicha práctica, por lo cual dista de generar un mayor valor agregado en su labor. 
Para ilustrar mejor, The Institute of Internal Auditors (2017) menciona los siguientes ejemplos:

- Detectar los gastos innecesarios.

- Identificar las advertencias de "bandera roja".

- Verificar los registros y los estados financieros.

- Evaluar el cumplimiento de las normas y reglamentaciones.

- Investigar el fraude.

- Promover la ética.

- Informar a la alta dirección y al consejo de administración.

- Identificar los riesgos y proporcionar aseguramiento sobre los controles (p. 5).

En relación con dichos ejemplos, todos se pueden tomar como referencia para que las UAI puedan detectar riesgos y se valore si se debe o no realizar algún cambio en pro del buen gobierno institucional. Así las cosas, aplicado a las instituciones públicas, el identificar los gastos innecesarios, por ejemplo, va de la mano con la contratación administrativa, pago de remuneraciones, entre otros.

Igualmente, el identificar las advertencias de "bandera roja" está relacionado con los servicios preventivos de advertencia, pues el beneficio de estos es alertar lo antes posible sobre situaciones que pueden perjudicar a la organización. Asimismo, la información financiera es muy importante, por lo que verificar los registros y estados financieros le permite al personal encargado de la auditoría interna determinar elementos que podría prevenir.

De igual manera, los servicios preventivos contribuyen en la evaluación del cumplimiento de las normas y reglamentaciones por parte de la administración, dado que en el sector público hay un ordenamiento jurídico y técnico el cual debe ser acatado por parte de esta para la buena gestión institucional.

Cabe agregar que la UAI se percibe como una unidad de confianza; debido a ello, se debe promover la ética entre su personal. Al mismo tiempo, dada su posición en la estructura orgánica, debe informar a la alta dirección y al consejo de administración sobre lo identificado y asesorarlos en aquello que resulte necesario.

Además, por cuanto la auditoría interna tiene su permanencia en la organización, puede abarcar asuntos relacionados con el sistema de control interno, gobierno, gestión de riesgo, aspectos administrativos, sustantivos de la institución, presupuestarios, entre otros; todo lo cual le permite generar valor agregado a la institución al reforzar la transparencia; así las cosas, comunica y advierte sobre problemas que se pueden generar a futuro.

Acerca de concebir que estos servicios deban darse en un sentido positivo $y$ en un marco de cordialidad, se obtuvo que un $86 \%$ de las personas encargadas de la UAI considera que siempre debe ser así; pero un $14 \%$ opina que solo algunas veces. De forma similar, un $86 \%$ del personal técnico colaborador considera que siempre, un $12 \%$ opina que solo algunas veces y un $2 \%$ indica que nunca.

Según la Contraloría General de la República (2012), los servicios preventivos deben "expresarse en términos de cortesía, profesionalismo y cooperación, y sin afán de crítica o juzgamiento, de modo que agregue valor al desempeño institucional” (p. 2).

Es decir, la mayoría del personal a cargo de las UAI concuerda con dicho planteamiento, pues consideran importante brindar dichos servicios de forma profesional, en un sentido positivo y con cordialidad, de forma que contribuyan a la buena administración; por lo tanto, es una práctica que se debe expandir a las demás UAI.

Luego, con el cuestionamiento relacionado con un momento específico para brindar estos servicios, según la opinión del personal de auditoría interna encuestado, un 41\% señala que siempre 
contribuyen en la realización de estos servicios, al mismo tiempo que se está dando la conducta o acción de la administración de la cual se debe advertir o asesorar; sin embargo, un 36\% opina que algunas veces y un $23 \%$ considera que nunca.

En este sentido, la Contraloría General (2012) menciona:

Puede brindarse a priori si la auditoría interna identifica la intención antes de que se convierta en conducta o decisión, o de manera concomitante. En el primer caso, procurará prevenir a la administración para que valore la intención; en el otro, su fin será que se valoren otras opciones (p. 2).

Con base en dicha argumentación, solamente un 41\% de las personas encargadas de la auditoría interna encuestadas considera llevar a cabo estos servicios al mismo tiempo que está sucediendo el evento; de esta forma, la administración puede revertir cualquier efecto negativo y atender de forma oportuna las observaciones de la UAI, en beneficio de la organización.

Por otro lado, un porcentaje importante de las respuestas recibidas indican que no se lleva a cabo esa práctica; de lo cual se determina que se están dejando de brindar insumos de forma oportuna. Ello conlleva a que la Administración Activa perciba que la UAI no es efectiva a la hora de emitir sus productos, en el tema de oportunidad.

Al respecto, Castilla Torres (2015) menciona "Se debe tener claro que la auditoría, además de los controles posteriores tradicionales, puede generar herramientas que minimicen la ocurrencia de los hechos anómalos detectados y en gran medida faciliten la labor de las entidades" (p. 69).

En este sentido, se presenta más de la mitad de las personas encuestadas, quienes respondieron acerca de implementar esta buena práctica en sus UAI; por lo cual están generando instrumentos para alertar cuando la administración esté por tomar alguna decisión relacionada con un hecho anómalo detectado, de manera que se pueda prevenir y suministrar la debida justificación de forma oportuna.

Sin embargo, se determina que en una proporción similar, los colaboradores opinan que no se elaboran instrumentos e insumos para alertar acerca de posibles incumplimientos de la normativa a la Administración Activa; por lo tanto, se percibe la necesidad de que se incorpore dicha práctica en todas las UAI.

\section{Dificultades que se presentan al realizar los servicios preventivos de asesoría $y$ advertencia}

En relación con la tercera categoría de análisis de este estudio, se realizaron 14 preguntas, de las cuales, para efectos de análisis, se despliegan los porcentajes de los ítems 37, 38, 47 y 49, dado que obtuvieron las puntuaciones más destacadas o relevantes, altas y bajas, para las percepciones positivas y negativas; con la finalidad de contrastar las opiniones de la población objeto de estudio de acuerdo con el sustento teórico y conceptual de la investigación. Además, los Anexos 1 y 2 muestran el cuestionario completo aplicado.

Respecto a si los servicios preventivos se pueden afectar por la omisión de algunas materias que son competencia de las UAI, el 68\% de las personas a cargo de las UAI coincide en que algunas veces sí, un $18 \%$ indica que siempre pasa y solamente un $14 \%$ indica que nunca es así.

En observancia a dichas respuestas, se deduce que para las UAI, una barrera que enfrentan al realizar servicios preventivos es el omitir materias de su competencia; por lo cual se limita la prestación de estos servicios en un reducido campo de temas. En tal sentido, la Contraloría General de la República, grupo de Auditores Internos del Sector Público (2012) hace una recopilación de temáticas que las UAI pueden considerar dentro de este tipo de servicios; a saber: 
... fundamentalmente los procesos de control interno, valoración de riesgos y dirección, aportando comentarios, criterios u observaciones que lleven a garantizar su efectividad, así como sobre los objetivos del sistema de control interno establecidos en el ordenamiento jurídico.

Por otra parte, la asesoría puede estar complementada con otros temas tales como:

- Aspectos operativos y administrativos

- Aspectos contables

- Contratación administrativa

- Aspectos sustantivos de la entidad

- Aspectos presupuestarios

- Gobierno corporativo (p. 6).

Sobre la base de las consideraciones anteriores, las temáticas que las UAI pueden abordar en el estudio de servicios preventivos se visualizan en áreas multidisciplinarias y responden a las necesidades tanto de la institución como de la sociedad, pues se espera que dichos servicios generen valor público y organizacional.

Según se ha citado, los asuntos sobre los que una UAI puede realizar servicios preventivos se refieren entre otros a: la administración, la operación, los modelos de control, la previsión de riesgos, presupuesto, contratación administrativa, aspectos sustantivos; por mencionar algunos de los aspectos en los que se requiere conocimiento, con el propósito de garantizar una idoneidad profesional que como especialistas en auditoría interna pueden ofrecer.

Es evidente, entonces, que un alto porcentaje de las UAI no se han apropiado plenamente de los diferentes asuntos por abordar en los servicios preventivos; como consecuencia, no se realiza una gestión adecuada en la prestación de estos y se pierde una ventaja competitiva para las UAI, por cuanto no se generan insumos para la toma de decisiones de la administración.

Así las cosas, un 57\% del personal técnico colaborador de las UAI opina que algunas veces puede existir pasividad en la gestión de los servicios preventivos; por su parte, un $29 \%$ indica que nunca pasa $y$ un $14 \%$ indica que siempre se da.

Como puede apreciarse, en su mayoría, el personal de las UAI opina que hay pasividad cuando se trata de realizar asesorías y advertencias; esto podría estar ocurriendo por cuanto se estén omitiendo materias de competencia de estas unidades, y por lo tanto, se limita la prestación de estos servicios a un reducido campo de asuntos.

En cuanto a establecer acciones para que la UAI gane credibilidad en la organización, se desprende que un $73 \%$, desde la perspectiva de los auditores internos, siempre lo realiza, y un $27 \%$ señala que algunas veces. Por otra parte, un $57 \%$ desde la perspectiva de los colaboradores de las UAI indican que siempre sucede, un 30\% considera que algunas veces y un 13\% opina que nunca.

Referente a dichas posiciones, se considera que un buen porcentaje es favorable; por lo tanto, el personal encargado de las auditorías internas está siendo consciente de que la imagen que proyecta puede afectarlos o beneficiarlos desde la óptica en la cual lo realicen. En este sentido, mantener una conducta ética es crucial para que la UAI pueda proporcionar un asesoramiento verosímil.

$\mathrm{Al}$ respecto, Chambers (2017) indica "Un error ético de un auditor interno puede menoscabar la confianza no solo en esa persona, sino también en aquellos que lo rodean" (p. 18). En consecuencia, una falta a la ética puede hacer perder la credibilidad de la UAI, y esto no se presenta solo cuando se da la acción indebida; sino cuando el personal encargado de las auditorías internas centra sus actividades en algo repetitivo, sin innovación, ni búsqueda de nuevas formas de realizar los trabajos; es decir, actuando reactivamente en lugar de buscar el bienestar de su organización y, por ende, del bien social común. 
Por lo tanto, de acuerdo con la perspectiva de las personas encuestadas, están siendo cautelosas, al brindar servicios con profesionalismo, cumpliendo con las normas y principios éticos como lo son la integridad, objetividad, independencia y competencia, y estar comprometidas con su labor para garantizar ser asesores de confianza en la organización en la cual se desempeñan.

En relación con gestionar cada periodo, el requerimiento de recursos para realizar servicios preventivos, la perspectiva de las personas encargadas de las auditorías internas es que un $86 \%$ considera que siempre lo hace; un $9 \%$ algunas veces y un 5\% nunca. Por su parte, el personal técnico colaborador opina en un 54\% siempre lo hace; mientras que un $21 \%$ solo algunas veces y un $25 \%$ considera que nunca.

Con referencia a lo anterior, se considera que las UAI del sector público costarricense, en su mayoría, están gestionando los recursos que requieran para desarrollar este tipo de servicios, por cuanto, según la Contraloría General de la República (2018), en el acápite 6.1.2 inciso a) señala:

a. La Auditoría Interna - Le corresponde formular técnicamente y comunicar al jerarca el requerimiento de los recursos necesarios para asegurar el cumplimiento de las competencias de la actividad de auditoría interna, así como dar seguimiento al trámite y los resultados de la solicitud, a fin de emprender cualesquiera medidas que sean procedentes en las circunstancias conforme a estas directrices y a las demás regulaciones del ordenamiento que sean aplicables. Asimismo, en la figura de su titular y como parte de la responsabilidad por la administración de sus recursos, debe rendir cuentas ante el jerarca por el uso que haga de los recursos, de conformidad con el plan de trabajo respectivo (acápite 6.1.2).

Es pues la misma auditoría interna la responsable de determinar la necesidad de sus recursos y gestionarla ante el jerarca para su dotación respectiva; además, de darle seguimiento a dicho requerimiento $y$ en dado caso, buscar la forma de obtener un resultado razonable en dicha gestión; además, funge como responsable de la administración de aquellos que le han sido otorgados para la realización de su trabajo; no obstante, es posible que no cuente con todos los recursos necesarios, por cuanto son limitados y se deben invertir bien.

\section{CONCLUSIONES}

Las conclusiones se presentan según las categorías de análisis definidas en el estudio, las cuales se detallan seguidamente.

\section{Metodologías de las UAI utilizadas para brindar servicios preventivos de asesoría y advertencia}

1. El estudio muestra que hay jefaturas de auditoría interna que no utilizan un instrumento de gestión que les facilite la prestación de los servicios preventivos; no obstante, el personal técnico colaborador, en su mayoría, sí emplean un instrumento de gestión en la labor de estos servicios.

2. Asimismo, el estudio determina que el personal encargado de las UAI no establece un proceso de planeamiento de metas de mediano plazo, respecto a la prestación de los servicios preventivos de asesorías y advertencias.

3. Se determina que las auditorías internas atienden permanentemente las solicitudes de asesoría que realiza la administración, en apego a la normativa aplicable. 
4. También, el estudio destaca que, de acuerdo con la percepción de la población objeto de estudio, un alto porcentaje de UAI considera necesario brindar los servicios preventivos de asesorías.

5. Se encontró que la mayoría del personal encargado de las auditorías internas promueve la ejecución de los servicios preventivos de manera escrita; por lo cual, estos quedan debidamente documentados.

6. Se determinó que, pese a que un alto porcentaje de las personas encargadas de la auditoría interna y del personal técnico colaborador velan por llevar un registro de los servicios preventivos brindados, en el cual se evidencie el tiempo y recursos utilizados, un porcentaje representativo de los responsables de esta área no realiza dicha práctica.

7. Además, en las respuestas obtenidas tanto de las personas a cargo de las auditorías interna como del personal técnico colaborador de las UAI, se determinó que, a pesar de que más de la mitad considera que la Administración Activa comprende la importancia de las advertencias, también hubo una perspectiva importante de quiénes opinaron que no es así.

8. En el estudio se comprobó que, pese a que más del $50 \%$ de la población objeto de estudio opina que se confrontan y analizan las acciones tomadas por la administración con respecto a los asuntos objeto de advertencia; también se encontró un porcentaje importante de estos que solamente lo realiza algunas veces e incluso, en el caso del personal técnico colaborador, un porcentaje más bajo opina que nunca se realiza; lo cual se contrapone con las buenas prácticas, por ello no se valida si se materializó o no el efecto negativo o incumplimiento normativo del cual se advirtió.

\section{Utilidades de los servicios preventivos de asesorías y advertencias}

1. En el estudio, se determinó que, a pesar de que algunas UAI tienen la práctica de elaborar instrumentos o insumos para alertar posibles incumplimientos; también se encontró un porcentaje importante de aquellas que no lo están haciendo $y$, por ende, no cuentan con instrumentos para alertar posibles incumplimientos.

2. Por otra parte, el estudio muestra que de la percepción tanto de las personas encargadas de las auditorías internas como del personal técnico colaborador, más del 50\% ejecuta acciones para identificar, a través de los servicios preventivos, los posibles riesgos que afectarían de forma negativa a la gestión institucional; no obstante, también se encontró un porcentaje importante que solamente lo realiza algunas veces o inclusive nunca, lo cual se contrapone con las buenas prácticas, en cuanto a prevenir las vulnerabilidades de la organización, por lo que se puede ver afectado el logro de los objetivos institucionales, en caso de que estas se materialicen.

3. También, el estudio destaca que, de acuerdo a la percepción de la población objeto de estudio, un alto porcentaje de UAI considera que los servicios preventivos deben darse en un sentido positivo y en un marco de cordialidad, dado que es importante brindar dichos servicios de forma profesional, para contribuir a la buena administración.

4. Aunque se comprueba que un porcentaje de las personas encargadas de las auditorías internas considera que lleva a cabo estos servicios al mismo tiempo que está sucediendo el evento; también, un porcentaje importante de las respuestas recibidas señala que no se lleva a cabo esa práctica; por lo cual se están dejando de brindar insumos de forma oportuna. 


\section{Dificultades que se presentan al realizar los servicios preventivos de asesoría y advertencia}

1. El estudio muestra que las personas encargadas de las auditorías internas consideran que, algunas veces, los servicios preventivos se pueden ver afectados por la omisión de algunas materias de su competencia, incluso algunos opinan que siempre sucede esto, y solo la percepción que corresponde a un $14 \%$ se inclina a que esto nunca sucede. En observancia a dichas respuestas, se deduce que para las UAI, una barrera que enfrentan al realizar servicios preventivos es el omitir materias de su competencia; por lo cual se limita la prestación de estos servicios en un reducido campo de temas.

2. Además, de acuerdo con el estudio, el personal técnico colaborador en su mayoría considera que algunas veces hay pasividad cuando se trata de realizar servicios preventivos, incluso algunos opinan que siempre sucede esto. En observancia a dichas respuestas, se deduce que esto podría estar ocurriendo por cuanto se estén omitiendo materias de competencia de estas unidades y, por lo tanto, se limita la prestación de estos servicios a un reducido campo de asuntos. Por otra parte, una percepción del $29 \%$ se inclina a que esto nunca sucede.

3. De acuerdo con la percepción las personas encargadas de las auditorías internas y el personal técnico colaborador, las UAI sí establecen acciones para que la Unidad de Auditoría Interna gane credibilidad en la organización; esto es favorable, pues deben ser conscientes de que la figura proyectada puede afectarlos o beneficiarlos.

4. Finalmente, de acuerdo con la percepción de las personas encargadas de las auditorías internas y el personal técnico colaborador, un porcentaje importante considera que se están gestionando los requerimientos de recursos necesarios para realizar servicios preventivos en las UAI; no obstante, del personal técnico colaborador, un porcentaje significativo considera que solo algunas veces o incluso indican que nunca sucede; por ello se muestra un incumplimiento a la normativa existente y evidencia debilidad en las UAI, en este sentido.

\section{RECOMENDACIONES}

Las recomendaciones para cada una de las variables son las siguientes:

\section{Metodología de las Unidades de Auditoría Interna para el aseguramiento de la calidad}

1. Seguir fomentando la utilización de un instrumento de gestión que contenga tareas concretas y específicas para realizar servicios preventivos de asesorías y advertencias en las UAI e incentivar a aquellos que aún no disponen de uno para que adquieran esta buena práctica.

2. Planificar metas a mediano plazo en lo que resulte procedente, para la prestación de servicios preventivos de asesorías y advertencias.

3. Mantener la buena práctica de considerar las solicitudes de asesoría que realiza el jerarca de la institución, en cumplimiento de lo normado por la CGR.

4. Incorporar en la gestión de las UAI el desarrollo de los servicios preventivos de asesorías, una vez se comprenda la importancia y necesidad que representan para la institución.

5. Expandir a todas las UAI, la práctica de realizar de manera escrita los servicios preventivos, de modo que quede debidamente documentado el trabajo del auditor.

6. Expandir a todas las UAI la práctica de llevar un registro de los servicios preventivos brindados, en el que se evidencie el tiempo y recursos utilizados. 
7. Continuar fomentando la buena práctica de darle seguimiento a las acciones tomadas por la administración, respecto a asuntos objeto de advertencia y promover dicha práctica en las UAI que no la realizan.

\section{Utilidades de los servicios preventivos de asesorías y advertencias}

1. Fomentar la instrumentalización por parte de las UAI, de instrumentos e insumos para alertar acerca de posibles incumplimientos a la normativa por parte de la Administración Activa, en procura del bienestar de esta.

2. Instrumentalizar acciones clave de los servicios preventivos, con el fin de identificar riesgos para prevenir a la administración de ellos y minimizar el impacto si se diera alguno.

3. Continuar fomentando en las UAI la buena práctica de brindar los servicios preventivos en términos de cortesía, profesionalismo y cooperación, de modo que agregue valor al desempeño institucional.

4. Agregar al ejercicio de las UAI la realización de servicios preventivos al mismo tiempo que se está dando la conducta inapropiada por parte de la administración; de modo que sirva de insumo para la toma de decisiones de la Administración.

5. Agregar al ejercicio de las UAI la realización de servicios preventivos de previo a que se dé la conducta inapropiada por parte de la administración, de modo que sirva de insumo para la toma de decisiones de la Administración.

\section{Dificultades que se presentan al realizar los servicios preventivos de asesoría y advertencia}

1. Incorporar dentro de las prácticas de planificación de los servicios preventivos, las temáticas de administración, operación, modelos de control, previsión de riesgos, presupuesto, contratación administrativa, aspectos sustantivos, entre otros que le son de su competencia; con el propósito de garantizar una idoneidad profesional que, como profesionales a cargo de la auditoría interna, pueden ofrecer a través de estos servicios.

2. Incorporar dentro de las prácticas de planificación de los servicios preventivos, las temáticas de administración, operación, modelos de control, previsión de riesgos, presupuesto, contratación administrativa, aspectos sustantivos, entre otros que le son de su competencia; con el propósito de garantizar una idoneidad profesional que, como profesionales a cargo de la auditoría interna, pueden ofrecer.

3. Expandir a todas las UAI del sector público, la práctica de realizar servicios preventivos sobre temas administrativos, para que agreguen valor a la gestión institucional y confianza a la información presentada por la administración de la organización.

4. Continuar fomentando a todas las UAI del sector público, la práctica de realizar servicios preventivos sobre temas sustantivos, para que agreguen valor a la gestión institucional.

5. Seguir fomentando a todas las UAI del sector público, la práctica de advertir cuando sea de su conocimiento, las posibles faltas que está cometiendo la administración, por ejemplo, el despilfarro y el fraude.

6. Expandir a todas las UAI del sector público, la práctica de establecer acciones para que estas ganen y establezcan credibilidad en sus organizaciones a través de la prestación de los servicios preventivos; por ejemplo, brindar servicios con profesionalismo, cumplimiento con las normas y principios éticos como la integridad, objetividad, independencia y competencia; $y$, estar comprometidos con su labor para garantizar ser asesores de confianza en la organización en la que se desempeñan. 
7. Continuar fomentando en todas las UAI, la práctica de gestionar el otorgamiento de recursos para la capacitación y actualización del personal en los temas que abordan los servicios preventivos. Al respecto, la capacitación debe ser permanente y con un enfoque de mejora continua para que la profundidad y alcance de las revisiones sean efectivas, $y$ garanticen razonablemente el control de las operaciones y el resguardo de los intereses organizacionales.

Por su parte, como posible futura línea de investigación, se considera útil elaborar un artículo científico que desarrolle una propuesta metodológica para la prestación de los servicios preventivos de asesorías y advertencias; la cual sirva de aplicación a cualquier UAI, sean estas unipersonales o hasta una unidad de 100 funcionarios o más.

\section{REFERENCIAS}

Arellano Elizalde, D., Calleja Calvario, A., Caudillo Flores, K. G., Cruz Pizarro, G., Estrada González, Y. y Palma Herrera, A. A. (2013). La auditoría operacional-administrativa y el contador público. Metodología aplicación práctica (Tesis de Licenciatura). Instituto Politécnico Nacional, México. https://tesis.ipn.mx/handle/123456789/19921

Asamblea Legislativa de la República de Costa Rica (2002). Ley General de Control Interno (Ley 8292). https://www.pgrweb.go.cr/scij/Busqueda/Normativa/Normas/nrm_texto_completo.asp x?param1=NRTC\&nValor1=1\&nValor2=49185\&nValor3=52569\&strTipM=TC

Castilla Torres, L. B. (2015). La auditoría como ejercicio generador de herramientas gerenciales para reducir los riesgos de fraude en los entes económicos. Saber, Ciencia y Libertad, 10(2), 63-74. https://doi.org/10.22525/sabcliber.2015v10n2.6374

Contraloría General de la República (2009). Normas para el ejercicio de la Auditoría Interna en el Sector Público. R-DC-119-2009. https://cgrfiles.cgr.go.cr/publico/docsweb/documentos/ auditoria/auditoria-interna/normas-ejercicio-ai-x.pdf

Contraloría General de la República (2012). DFOE-ST-0033 (Oficio No 02836). https://cgrfiles.cgr. go.cr/publico/docs_cgr/2012/SIGYD_D_2012004320.pdf

Contraloría General de la República (2018). DFOE-PG-0154 (Oficio No 4800). https://cgrfiles.cgr. go.cr/publico/docs_cgr/2018/SIGYD_D_2018005393.pdf

Contraloría General de la República (2018). Lineamientos sobre gestiones que involucran a la auditoría interna presentadas ante la Contraloría General de la República, $R-D C$-832018. https://cgrfiles.cgr.go.cr/publico/docsweb/documentos/auditoria/auditoria-interna/ lineamientos-auditoria-interna-10-2018.pdf

Contraloría General de la República, grupo de Auditores Internos del Sector Público (2012). Guía Técnica sobre el Servicio de Asesoría de las Auditorías Internas del Sector Público. https:// www.tec.ac.cr/sites/default/files/media/doc/guia_tecnica_sobre_servicio_de_asesoria_de_ las_auditorias_internas_del_sector_publico_-_adoptada_.pdf

Chambers, R. (2017). Asesores de Confianza. Atributos clave de los auditores internos excepcionales. The Internal Audit Foundation

Defensoría de los Habitantes de la República (2016). Manual de procedimientos de la auditoría interna. http://www.dhr.go.cr/transparencia/jerarcas_decisiones/manual_y_procedimientos_ auditoria/manual_y_procedimientos_de_la_auditoria_interna.pdf

Hernández Sampieri, R., Fernández Collado, C. y Baptista Lucio, P. (1991). Metodología de la investigación. McGraw-Hill/ Interamericana Editores.

Hernández Sampieri, R., Fernández Collado, C. y Baptista Lucio, P. (2014). Metodología de la investigación. McGraw-Hill/ Interamericana Editores. 
Instituto Internacional de Auditores Internos (2017). Normas internacionales para el ejercicio profesional de la auditoría interna. https://na.theiia.org/translations/PublicDocuments/IPPFStandards-2017-Spanish.pdf

Murgueytio Montenegro, J. A. (2017). Modelo de gestión para las unidades de auditoría interna del sector público ecuatoriano. Editorial Universitaria

The Institute of Internal Auditors (2017). Perspectivas y percepciones globales: auditoría interna y auditoría externa. Funciones distintivas para la administración de una organización (8 ed.). https://global.theiia.org/translations/PublicDocuments/GPI-Distinctive-Roles-inOrganizational-Governance-Spanish.pdf 
VII. ANEXOS

\author{
ANEXO 1 \\ Universidad Estatal a Distancia \\ Sistema de Estudios de Posgrado (SEP) \\ ESCUELA CIENCIAS DE LA ADMINISTRACIÓN (ECA)
}

\title{
CUESTIONARIO DIRIGIDO AL AUDITOR INTERNO
}

El siguiente cuestionario tiene como propósito analizar los servicios preventivos de asesoría y advertencia que la unidad de auditoría interna (UAI) realiza como parte de las funciones que le son atribuidas. Este trabajo corresponde a una investigación de la Maestría en Auditoría Gubernamental de la Universidad Estatal a Distancia (UNED). La información brindada será de uso confidencial y anónima. ¡De antemano le agradezco su colaboración!

\section{GENERALIDADES}

Nombre de la unidad de auditoría interna

Indique su nombre (opcional)

Identifique el cargo para el cual se desempeña ( ) Auditor Interno ( ) Sub Auditor

Género: ( ) Femenino ( ) Masculino

Condición laboral: ( ) En propiedad ( ) Interino (a)

Grado profesional: ( ) Bachiller universitario ( ) Licenciatura ( ) Maestría ( ) Doctorado

¿Cuántos años ha laborado en la Auditoría Interna de la entidad?:

( ) Menos de un año

( ) De 1 a 5 años

( ) De 6 a 10 años

( ) Más de 10 años

\section{Parte: Metodología, Servicios preventivos: Asesoría y Advertencia}

A continuación, se le presentan una serie de enunciados relacionados con Metodología, Servicios preventivos: Asesoría y Advertencia que brinda la UAI. Según su criterio marque con una "x" la frecuencia con la que éstas se implementan en la institución para la cual labora. Por favor responda las siguientes preguntas con la subsiguiente escala de valoración: 


\begin{tabular}{|c|c|c|c|}
\hline $\begin{array}{l}\text { USTED COMO RESPONSABLE DE LA UAI EN LA IMPLEMENTACIÓN DE LOS } \\
\text { SERVICIOS PREVENTIVOS DE ASESORÍA Y ADVERTENCIA }\end{array}$ & Siempre & $\begin{array}{l}\text { Algunas } \\
\text { veces }\end{array}$ & Nunca \\
\hline $\begin{array}{l}\text { 1. Utiliza un instrumento de gestión (físico o digital) para la realización de estos } \\
\text { servicios }\end{array}$ & & & \\
\hline 2. Establece fases articuladas para el desarrollo de estos servicios & & & \\
\hline 3. Implementa tareas concretas y específicas para el desarrollo de estos servicios & & & \\
\hline 4. Planea metas de corto plazo respecto a la prestación de estos servicios & & & \\
\hline 5. Planea metas de mediano plazo respecto a la prestación de estos servicios & & & \\
\hline 6. Planea metas de largo plazo respecto a la prestación de estos servicios & & & \\
\hline 7. Propicia la realización de servicios preventivos de asesoría & & & \\
\hline 8. Participa en la realización de servicios preventivos de asesoría & & & \\
\hline $\begin{array}{l}\text { 9. Plantea el establecimiento de observaciones, criterios y consejos para el sujeto } \\
\text { pasivo producto de las asesorías. }\end{array}$ & & & \\
\hline $\begin{array}{l}\text { 10. Toma en cuenta las solicitudes de asesoría que realiza el jerarca de su } \\
\text { institución. }\end{array}$ & & & \\
\hline $\begin{array}{l}\text { 11. Toma en cuenta las solicitudes de asesoría que realizan otros colaboradores } \\
\text { de la institución }\end{array}$ & & & \\
\hline $\begin{array}{l}\text { 12. Toma en cuenta las solicitudes de asesoría que realizan otros interesados de } \\
\text { la institución }\end{array}$ & & & \\
\hline $\begin{array}{l}\text { 13. Comprueba si la administración acata los criterios que surgen de las asesorías } \\
\text { para la toma de decisiones. }\end{array}$ & & & \\
\hline $\begin{array}{l}\text { 14. Considera que los servicios preventivos se emiten conforme al ordenamiento } \\
\text { jurídico y técnico costarricense. }\end{array}$ & & & \\
\hline $\begin{array}{l}\text { 15. Vigila que los servicios preventivos se ejecutan según los principios de } \\
\text { independencia y objetividad del auditor }\end{array}$ & & & \\
\hline $\begin{array}{l}\text { 16. Plantea el desarrollo de estudios posteriores sobre asuntos de los cuales se } \\
\text { emitió una asesoría. }\end{array}$ & & & \\
\hline 17. Considera necesario e importante brindar los servicios de asesoría & & & \\
\hline $\begin{array}{l}\text { 18. Concibe a la asesoría como un mecanismo para el logro de los objetivos } \\
\text { institucionales }\end{array}$ & & & \\
\hline $\begin{array}{l}\text { 19. Considera que a través de estos servicios se promueve la rendición de cuentas } \\
\text { por parte de la administración }\end{array}$ & & & \\
\hline 20. Promueve la implementación de estos servicios de forma verbal & & & \\
\hline 21. Promueve la ejecución de estos servicios de manera escrita & & & \\
\hline $\begin{array}{l}22 . \text { Vela porque todas los servicios preventivos brindados se incorporen en un } \\
\text { registro, donde se evidencie el tiempo y recursos que conllevó el realizarlos }\end{array}$ & & & \\
\hline $\begin{array}{l}\text { 23. Establece los lineamientos para la realización de advertencias hacia el sujeto } \\
\text { pasivo }\end{array}$ & & & \\
\hline 24. Participa en la realización colaborativa de advertencias a la administración. & & & \\
\hline $\begin{array}{l}\text { 25. Revisa periódicamente el marco que debe cumplir el órgano pasivo, con el fin } \\
\text { de detectar posibles infracciones por parte de este }\end{array}$ & & & \\
\hline $\begin{array}{l}\text { 26. Considera que la administración comprende que la importancia de las } \\
\text { advertencias radica en prevenir una afectación negativa a la gestión institucional }\end{array}$ & & & \\
\hline $\begin{array}{l}\text { 27. Confronta y analiza las acciones tomadas por la administración con respecto } \\
\text { a los asuntos objeto de advertencia }\end{array}$ & & & \\
\hline
\end{tabular}




\section{Parte: Utilidades de los servicios preventivos de asesorías y advertencias}

A continuación, se le presentan una serie de enunciados relacionados con las utilidades que se derivan de los servicios preventivos de asesorías y advertencias que brinda la UAI. Según su criterio marque con una " $\mathrm{x}$ " la frecuencia con la que éstas se implementan en la institución para la cual labora. Por favor responda las siguientes preguntas con la subsiguiente escala de valoración:

\begin{tabular}{|c|c|c|c|}
\hline $\begin{array}{l}\text { USTED COMO RESPONSABLE DE LA UAI EN LA IMPLEMENTACIÓN DE LOS } \\
\text { SERVICIOS PREVENTIVOS DE ASESORÍA Y ADVERTENCIA }\end{array}$ & Siempre & $\begin{array}{l}\text { Algunas } \\
\text { veces }\end{array}$ & Nunca \\
\hline $\begin{array}{l}\text { 28. Elabora Instrumentos e insumos que permiten alertar posibles } \\
\text { incumplimientos a la normativa }\end{array}$ & & & \\
\hline $\begin{array}{l}\text { 29. Desarrolla el acompañamiento institucional a través de la prestación de estos } \\
\text { servicios }\end{array}$ & & & \\
\hline 30. Vela por la gestión y el buen gobierno de la organización & & & \\
\hline $\begin{array}{l}\text { 31. Ejecuta acciones para identificar a través de los servicios preventivos, los } \\
\text { posibles riesgos que afectarían de forma negativa a la gestión institucional }\end{array}$ & & & \\
\hline $\begin{array}{l}\text { 32. Colabora con propuestas de mejora proactiva institucional a través de estos } \\
\text { servicios. }\end{array}$ & & & \\
\hline $\begin{array}{l}\text { 33. Concibe que estos servicios deben darse en un sentido positivo y en un marco } \\
\text { de cordialidad }\end{array}$ & & & \\
\hline $\begin{array}{l}\text { 34. Considera que estos servicios deben darse en un sentido de señalamiento o } \\
\text { crítica, para la mejora institucional. }\end{array}$ & & & \\
\hline $\begin{array}{l}\text { 35. Plantea servicios preventivos previos a una conducta o decisión del sujeto } \\
\text { pasivo }\end{array}$ & & & \\
\hline $\begin{array}{l}\text { 36. Contribuye en la realización de estos servicios al mismo tiempo que se está } \\
\text { dando la conducta o acción de la administración de la cual se debe advertir o } \\
\text { asesorar }\end{array}$ & & & \\
\hline
\end{tabular}

\section{Parte: Dificultades de los servicios preventivos de asesorías y advertencias}

A continuación, se le presentan una serie de enunciados relacionados con las utilidades que se derivan de los servicios preventivos de asesorías y advertencias que brinda la UAI. Según su criterio marque con una " $x$ " la frecuencia con la que éstas se implementan en la institución para la cual labora. Por favor responda las siguientes preguntas con la subsiguiente escala de valoración:

\begin{tabular}{|c|c|c|c|}
\hline $\begin{array}{l}\text { USTED COMO RESPONSABLE DE LA UAI EN LA IMPLEMENTACIÓN DE LOS } \\
\text { SERVICIOS PREVENTIVOS DE ASESORÍA Y ADVERTENCIA }\end{array}$ & Siempre & $\begin{array}{c}\text { Algunas } \\
\text { veces }\end{array}$ & Nunca \\
\hline $\begin{array}{l}\text { 37. Considera que estos servicios se pueden afectar por la omisión de algunas } \\
\text { materias de su competencia }\end{array}$ & & & \\
\hline 38. Existe pasividad en la gestión de estos servicios en su institución & & & \\
\hline $\begin{array}{l}\text { 39. Promueve la realización de estos servicios respecto a asuntos administrativos } \\
\text { de la institución }\end{array}$ & & & \\
\hline $\begin{array}{l}\text { 40. Promueve la realización de estos servicios en contratación administrativa de } \\
\text { la organización }\end{array}$ & & & \\
\hline $\begin{array}{l}\text { 41. Promueve la realización de estos servicios en temas de presupuesto } \\
\text { institucional }\end{array}$ & & & \\
\hline
\end{tabular}




\begin{tabular}{|c|c|c|c|}
\hline $\begin{array}{l}\text { USTED COMO RESPONSABLE DE LA UAI EN LA IMPLEMENTACIÓN DE LOS } \\
\text { SERVICIOS PREVENTIVOS DE ASESORÍA Y ADVERTENCIA }\end{array}$ & Siempre & $\begin{array}{l}\text { Algunas } \\
\text { veces }\end{array}$ & Nunca \\
\hline \multicolumn{4}{|l|}{$\begin{array}{l}\text { 42. Promueve la realización de estos servicios en asuntos sustantivos de la } \\
\text { organización }\end{array}$} \\
\hline \multicolumn{4}{|l|}{$\begin{array}{l}\text { 43. Considera que una dificultad para brindar estos servicios, es el temor a } \\
\text { efectuar funciones propias de la administración }\end{array}$} \\
\hline \multicolumn{4}{|l|}{$\begin{array}{l}\text { 44. Propone estrategias para advertir sobre las posibles faltas de la } \\
\text { administración, por ejemplo: despilfarro y fraude }\end{array}$} \\
\hline \multicolumn{4}{|l|}{ 45. Plantea estrategias para advertir sobre una posible ineficaz gobernanza } \\
\hline \multicolumn{4}{|l|}{$\begin{array}{l}\text { 46. Promueve espacios para discutir sobre faltas a la ética de modo que se } \\
\text { prevenga al personal de la auditoría interna para no cometerlas }\end{array}$} \\
\hline \multicolumn{4}{|l|}{$\begin{array}{l}\text { 47. Establece acciones para que la Unidad de Auditoría Interna gane credibilidad } \\
\text { en la organización }\end{array}$} \\
\hline \multicolumn{4}{|l|}{$\begin{array}{l}\text { 48. Gestiona el otorgamiento de recursos para actualizar y capacitar al personal } \\
\text { de la UAI. }\end{array}$} \\
\hline \multicolumn{4}{|l|}{$\begin{array}{l}\text { 49. Gestiona cada periodo el requerimiento de recursos para realizar servicios } \\
\text { preventivos UAI }\end{array}$} \\
\hline $\begin{array}{l}\text { 50. Considera que la limitación de recursos de la auditoría interna afecta la } \\
\text { realización de estos servicios }\end{array}$ & & & \\
\hline
\end{tabular}




\author{
ANEXO 2 \\ Universidad Estatal a Distancia \\ Sistema de Estudios de Posgrado (SEP) \\ ESCUELA CIENCIAS DE LA ADMINISTRACIÓN (ECA)
}

\title{
CUESTIONARIO DIRIGIDO AL PERSONAL TÉCNICO DE LA UNIDAD DE AUDITORÍA INTERNA
}

El siguiente cuestionario tiene como propósito analizar los servicios preventivos de asesoría y advertencia que la unidad de auditoría interna (UAI) realiza como parte de las funciones que le son atribuidas. Este trabajo corresponde a una investigación de la Maestría en Auditoría Gubernamental de la Universidad Estatal a Distancia (UNED). La información brindada será de uso confidencial y anónima. ¡De antemano le agradezco su colaboración!

\section{GENERALIDADES}

Nombre de la unidad de auditoría interna

Indique su nombre (opcional)

Identifique el cargo para el cual se desempeña ( ) Auditor Interno ( ) Sub Auditor

Género: ( ) Femenino ( ) Masculino

Condición laboral: ( ) En propiedad ( ) Interino (a)

Grado profesional: ( ) Bachiller universitario ( ) Licenciatura ( ) Maestría ( ) Doctorado

¿Cuántos años ha laborado en la Auditoría Interna de la entidad?:

( ) Menos de un año

( ) De 1 a 5 años

( ) De 6 a 10 años

( ) Más de 10 años

\section{Parte: Metodología, Servicios preventivos: Asesoría y Advertencia}

A continuación, se le presentan una serie de enunciados relacionados con Metodología, Servicios preventivos: Asesoría y Advertencia que brinda la UAI. Según su criterio marque con una "x" la frecuencia con la que éstas se implementan en la institución para la cual labora. Por favor responda las siguientes preguntas con la subsiguiente escala de valoración: 


\begin{tabular}{|c|c|c|c|}
\hline $\begin{array}{l}\text { USTED COMO RESPONSABLE DE LA UAI EN LA IMPLEMENTACIÓN DE LOS } \\
\text { SERVICIOS PREVENTIVOS DE ASESORÍA Y ADVERTENCIA }\end{array}$ & Siempre & $\begin{array}{c}\text { Algunas } \\
\text { veces }\end{array}$ & Nunca \\
\hline $\begin{array}{l}\text { 1. Utiliza un instrumento de gestión (físico o digital) para la realización de estos } \\
\text { servicios }\end{array}$ & & & \\
\hline 2. Establece fases articuladas para el desarrollo de estos servicios & & & \\
\hline 3. Implementa tareas concretas y específicas para el desarrollo de estos servicios & & & \\
\hline 4. Planea metas de corto plazo respecto a la prestación de estos servicios & & & \\
\hline 5. Planea metas de mediano plazo respecto a la prestación de estos servicios & & & \\
\hline 6. Planea metas de largo plazo respecto a la prestación de estos servicios & & & \\
\hline 7. Propicia la realización de servicios preventivos de asesoría & & & \\
\hline 8. Participa en la realización de servicios preventivos de asesoría & & & \\
\hline $\begin{array}{l}\text { 9. Plantea el establecimiento de observaciones, criterios y consejos para el sujeto } \\
\text { pasivo producto de las asesorías. }\end{array}$ & & & \\
\hline $\begin{array}{l}\text { 10. Toma en cuenta las solicitudes de asesoría que realiza el jerarca de su } \\
\text { institución. }\end{array}$ & & & \\
\hline $\begin{array}{l}\text { 11. Toma en cuenta las solicitudes de asesoría que realizan otros colaboradores } \\
\text { de la institución }\end{array}$ & & & \\
\hline $\begin{array}{l}\text { 12. Toma en cuenta las solicitudes de asesoría que realizan otros interesados de } \\
\text { la institución }\end{array}$ & & & \\
\hline $\begin{array}{l}\text { 13. Comprueba si la administración acata los criterios que surgen de las asesorías } \\
\text { para la toma de decisiones. }\end{array}$ & & & \\
\hline $\begin{array}{l}\text { 14. Considera que los servicios preventivos se emiten conforme al ordenamiento } \\
\text { jurídico y técnico costarricense. }\end{array}$ & & & \\
\hline $\begin{array}{l}\text { 15. Vigila que los servicios preventivos se ejecutan según los principios de } \\
\text { independencia y objetividad del auditor }\end{array}$ & & & \\
\hline $\begin{array}{l}\text { 16. Plantea el desarrollo de estudios posteriores sobre asuntos de los cuales se } \\
\text { emitió una asesoría. }\end{array}$ & & & \\
\hline 17. Considera necesario e importante brindar los servicios de asesoría & & & \\
\hline $\begin{array}{l}\text { 18. Concibe a la asesoría como un mecanismo para el logro de los objetivos } \\
\text { institucionales }\end{array}$ & & & \\
\hline $\begin{array}{l}\text { 19. Considera que a través de estos servicios se promueve la rendición de cuentas } \\
\text { por parte de la administración }\end{array}$ & & & \\
\hline 20. Promueve la implementación de estos servicios de forma verbal & & & \\
\hline 21. Promueve la ejecución de estos servicios de manera escrita & & & \\
\hline $\begin{array}{l}22 . \text { Vela porque todas los servicios preventivos brindados se incorporen en un } \\
\text { registro, donde se evidencie el tiempo y recursos que conllevó el realizarlos }\end{array}$ & & & \\
\hline $\begin{array}{l}\text { 23. Establece los lineamientos para la realización de advertencias hacia el sujeto } \\
\text { pasivo }\end{array}$ & & & \\
\hline 24. Participa en la realización colaborativa de advertencias a la administración. & & & \\
\hline $\begin{array}{l}\text { 25. Revisa periódicamente el marco que debe cumplir el órgano pasivo, con el fin } \\
\text { de detectar posibles infracciones por parte de este }\end{array}$ & & & \\
\hline $\begin{array}{l}\text { 26. Considera que la administración comprende que la importancia de las } \\
\text { advertencias radica en prevenir una afectación negativa a la gestión institucional }\end{array}$ & & & \\
\hline $\begin{array}{l}\text { 27. Confronta y analiza las acciones tomadas por la administración con respecto } \\
\text { a los asuntos objeto de advertencia }\end{array}$ & & & \\
\hline
\end{tabular}




\section{Parte: Utilidades de los servicios preventivos de asesorías y advertencias}

A continuación, se le presentan una serie de enunciados relacionados con las utilidades que se derivan de los servicios preventivos de asesorías y advertencias que brinda la UAI. Según su criterio marque con una " $\mathrm{x}$ " la frecuencia con la que éstas se implementan en la institución para la cual labora. Por favor responda las siguientes preguntas con la subsiguiente escala de valoración:

\begin{tabular}{|c|c|c|c|}
\hline $\begin{array}{l}\text { USTED COMO RESPONSABLE DE LA UAI EN LA IMPLEMENTACIÓN DE LOS } \\
\text { SERVICIOS PREVENTIVOS DE ASESORÍA Y ADVERTENCIA }\end{array}$ & Siempre & $\begin{array}{l}\text { Algunas } \\
\text { veces }\end{array}$ & Nunca \\
\hline $\begin{array}{l}\text { 28. Elabora Instrumentos e insumos que permiten alertar posibles } \\
\text { incumplimientos a la normativa }\end{array}$ & & & \\
\hline $\begin{array}{l}\text { 29. Desarrolla el acompañamiento institucional a través de la prestación de estos } \\
\text { servicios }\end{array}$ & & & \\
\hline 30. Vela por la gestión y el buen gobierno de la organización & & & \\
\hline $\begin{array}{l}\text { 31. Ejecuta acciones para identificar a través de los servicios preventivos, los } \\
\text { posibles riesgos que afectarían de forma negativa a la gestión institucional }\end{array}$ & & & \\
\hline $\begin{array}{l}\text { 32. Colabora con propuestas de mejora proactiva institucional a través de estos } \\
\text { servicios. }\end{array}$ & & & \\
\hline $\begin{array}{l}\text { 33. Concibe que estos servicios deben darse en un sentido positivo y en un marco } \\
\text { de cordialidad }\end{array}$ & & & \\
\hline $\begin{array}{l}\text { 34. Considera que estos servicios deben darse en un sentido de señalamiento o } \\
\text { crítica, para la mejora institucional. }\end{array}$ & & & \\
\hline $\begin{array}{l}\text { 35. Plantea servicios preventivos previos a una conducta o decisión del sujeto } \\
\text { pasivo }\end{array}$ & & & \\
\hline $\begin{array}{l}\text { 36. Contribuye en la realización de estos servicios al mismo tiempo que se está } \\
\text { dando la conducta o acción de la administración de la cual se debe advertir o } \\
\text { asesorar }\end{array}$ & & & \\
\hline
\end{tabular}

\section{Parte: Dificultades de los servicios preventivos de asesorías y advertencias}

A continuación, se le presenta una serie de enunciados relacionados con las dificultades que se derivan de los servicios preventivos de asesorías y advertencias que brinda la UAI. Según su criterio marque con una " $x$ " la frecuencia con la que éstas se implementan en la institución para la cual labora. Por favor responda las siguientes preguntas con la subsiguiente escala de valoración:

\begin{tabular}{|c|c|c|c|}
\hline $\begin{array}{l}\text { USTED COMO RESPONSABLE DE LA UAI EN LA IMPLEMENTACIÓN DE LOS } \\
\text { SERVICIOS PREVENTIVOS DE ASESORÍA Y ADVERTENCIA }\end{array}$ & Siempre & $\begin{array}{c}\text { Algunas } \\
\text { veces }\end{array}$ & Nunca \\
\hline $\begin{array}{l}\text { 37. Considera que estos servicios se pueden afectar por la omisión de algunas } \\
\text { materias de su competencia }\end{array}$ & & & \\
\hline 38. Existe pasividad en la gestión de estos servicios en su institución & & & \\
\hline $\begin{array}{l}\text { 39. Promueve la realización de estos servicios respecto a asuntos administrativos } \\
\text { de la institución }\end{array}$ & & & \\
\hline $\begin{array}{l}\text { 40. Promueve la realización de estos servicios en contratación administrativa de } \\
\text { la organización }\end{array}$ & & & \\
\hline $\begin{array}{l}\text { 41. Promueve la realización de estos servicios en temas de presupuesto } \\
\text { institucional }\end{array}$ & & & \\
\hline
\end{tabular}




\begin{tabular}{|c|c|c|c|}
\hline $\begin{array}{l}\text { USTED COMO RESPONSABLE DE LA UAI EN LA IMPLEMENTACIÓN DE LOS } \\
\text { SERVICIOS PREVENTIVOS DE ASESORÍA Y ADVERTENCIA }\end{array}$ & Siempre & $\begin{array}{l}\text { Algunas } \\
\text { veces }\end{array}$ & Nunca \\
\hline $\begin{array}{l}\text { 42. Promueve la realización de estos servicios en asuntos sustantivos de la } \\
\text { organización }\end{array}$ & & & \\
\hline $\begin{array}{l}\text { 43. Considera que una dificultad para brindar estos servicios, es el temor a } \\
\text { efectuar funciones propias de la administración }\end{array}$ & & & \\
\hline $\begin{array}{l}\text { 44. Propone estrategias para advertir sobre las posibles faltas de la } \\
\text { administración, por ejemplo: despilfarro y fraude }\end{array}$ & & & \\
\hline 45. Plantea estrategias para advertir sobre una posible ineficaz gobernanza & & & \\
\hline $\begin{array}{l}\text { 46. Promueve espacios para discutir sobre faltas a la ética de modo que se } \\
\text { prevenga al personal de la auditoría interna para no cometerlas }\end{array}$ & & & \\
\hline $\begin{array}{l}\text { 47. Establece acciones para que la Unidad de Auditoría Interna gane credibilidad } \\
\text { en la organización }\end{array}$ & & & \\
\hline $\begin{array}{l}\text { 48. Gestiona el otorgamiento de recursos para actualizar y capacitar al personal } \\
\text { de la UAI. }\end{array}$ & & & \\
\hline $\begin{array}{l}\text { 49. Gestiona cada periodo el requerimiento de recursos para realizar servicios } \\
\text { preventivos UAI }\end{array}$ & & & \\
\hline $\begin{array}{l}\text { 50. Considera que la limitación de recursos de la auditoría interna afecta la } \\
\text { realización de estos servicios }\end{array}$ & & & \\
\hline
\end{tabular}

Este artículo se encuentra disponible mediante la licencia Creative Commons Reconocimiento-NoComercial-SinObraDerivada 3.0 Costa Rica. Para mayor información escribir a revista.iice@ucr.ac.cr. 